\title{
The Effect of Breastfeeding on the Cognitive and Language Development of Children Under 3 Years of Age: Results of 'Balochistan-Early Childhood Development Project'
}

\author{
Meesha Iqbal $^{1}$, Ghazala Rafique ${ }^{2}$ and Sumera Aziz Ali ${ }^{1}$ \\ ${ }^{1}$ Department of Community Health Sciences, Aga Khan University, Stadium Road, P.O. Box 3500, Karachi 74800, Pakistan \\ ${ }^{2}$ Human Development Program, Aga Khan University, Stadium Road, P.O. Box 3500, Karachi 74800, Pakistan \\ ${ }^{*}$ Corresponding author: Meesha Iqbal, Department of Community Health Sciences, Aga Khan University, Stadium Road, P.O. Box 3500, Karachi 74800, Pakistan, Tel: \\ 0213486 4857; E-mail: meesha.iqbal@aku.edu
}

Received date: April 20, 2017; Accepted date: April 24, 2017; Published date: April 29, 2017

Copyright: () 2017 Iqbal M, et al. This is an open-access article distributed under the terms of the Creative Commons Attribution License, which permits unrestricted use, distribution, and reproduction in any medium, provided the original author and source are credited.

\begin{abstract}
Background: Breastfeeding is known to be an important factor in the overall growth and development of children. Breastfeeding is thought to lead to enhance cognitive and language development of a child. However, this association has not yet been scientifically and statistically established. This study aimed to explore this association in children under 3 years of age.
\end{abstract}

Methods: This was a secondary data-analysis of the baseline data of "Balochistan - Early Childhood Development Project". The final sample comprised of 604 children less than 3 years of age. The children were selected by three-stage stratified random sampling from three districts of Balochistan province; Gwadar, Quetta and Qilla Saifullah. The data for the duration of breastfeeding was categorized as less than 6 months, from 6 months to 12 months and greater than 12 months. The age appropriate language and cognitive development of children was assessed through the CDA (Care for development Appraisal) tool. We applied multivariate logistic regression model for the analysis.

Results: In unadjusted analysis, children breastfed for more than 12 months were at an advantage for cognitive and language development ( $\mathrm{COR}=2.91, \mathrm{cOR}=2.8 ; \mathrm{p}<0.05$; respectively). After adjusting for a range of co-variates this developmental advantage decreased to $\mathrm{aOR}=2.42$ for cognition and $\mathrm{aOR}=2.44$ for language respectively $(\mathrm{p}<0.05)$.

Conclusions: The duration for which the child is breast-fed is integral for his language and cognitive development. Based on our findings we recommend that breastfeeding should be promoted for more than 12 months to bring out the maximum benefit in the language and cognitive development of a child.

Keywords: Feeding breast; Cognitive function; Language developments

\section{Background}

Breastfeeding for long has been known to have a beneficial effect on the overall growth and development of children [1]. The effect of breastfeeding on the cognitive and language development of children has been widely studied. However, we still lack conclusive evidence to the actual benefit, if any, on these domains of child development. Some studies give an encouraging effect of breastfeeding whereas others point out that the positive impact is solely due to the effect of confounding factors.

According to the work by James et al. [2] breast-feeding was associated with significantly higher scores for cognitive development in children even after adjustment for appropriate key cofactors. His findings were contradicted by Asnat et al. [3] he found that much of the reported effect of breastfeeding on child neurodevelopment was due to confounding; maternal intelligence and socio-economic status being the noteworthy of the list.
As compared to cognitive development, little work has been done to see the link between breastfeeding and language development of children. Vasiliki et al. [4] pointed out that longer duration of breast feeding was associated with increased scores in cognitive, language and motor development at 18 months of age, independently from a wide range of parental and infant characteristics.

The notion of exclusive breastfeeding has been promoted for the last two decades. Most of the studies recommend exclusive breastfeeding for six months for optimal growth of the child [5]. However, there is dearth of data regarding the dose-response relationship of breastfeeding with cognitive and language development of children. Thus, we sought to investigate the effect of increasing the duration of breastfeeding on the language and cognitive development of children less than 3 years of age.

\section{Methods}

\section{Sampling}

This paper uses cross-sectional data collected from 604 children participating in the baseline survey of "Baluchistan-Early Childhood 
Citation: Iqbal M, Rafique G, Ali S (2017) The Effect of Breastfeeding on the Cognitive and Language Development of Children Under 3 Years of Age: Results of 'Balochistan-Early Childhood Development Project'. J Gen Pract (Los Angel) 5: 305. doi:10.4172/2329-9126.1000305

Page 2 of 8

Development Project", a quasi-experimental study [6]. This study was initiated to enhance the access, equity and quality of education in class Katchi, one and two of 75 government primary schools in three districts; Gwadar, Quetta and Qilla Saifullah; of Baluchistan province. The sample was selected through three stage stratified random sampling. In the first stage, number of children studying in nearest project focus schools to FRC (Family Resource Centre) was found in each district. In the second stage, selected households in the FRC catchment areas were visited and in the third stage, family having a 0-8 year old child was selected. All stages of the project were subject to rigorous ethical review by the Ethical Review Committee of Aga Khan University. The details of the parent study are mentioned elsewhere [6].

\section{Statistical methods}

Ideally, the causal effect of breastfeeding on the cognitive and language development of children would be assessed by a randomized control trial. Research ethics does not allow such randomization in which one group of children does not get breastfeeding, thus we are forced to use observational methods and statistical analysis to identify the effect of breastfeeding on outcome- language and cognitive development. We controlled for a large range of potentially confounding factors drawn from the "Balochistan - Early Childhood Development Project". Chi-square and Independent sample t- test were applied for initial analysis. Uni-variate logistic regression was done to assess the effect of independent factors on outcomes. All variables with p-value $<0.25$ were taken for the multivariate analysis. Multicollinearity was checked between the independent variables through Pearson and Spearman correlation. For none of the variables the correlation coefficient was beyond $50 \%$. The adjusted odds ratios were calculated in the multivariate regression by selecting the model with the smallest value of $-2 \log$ likelihood. The analysis was done using SPSS version 22 (Figure 1).

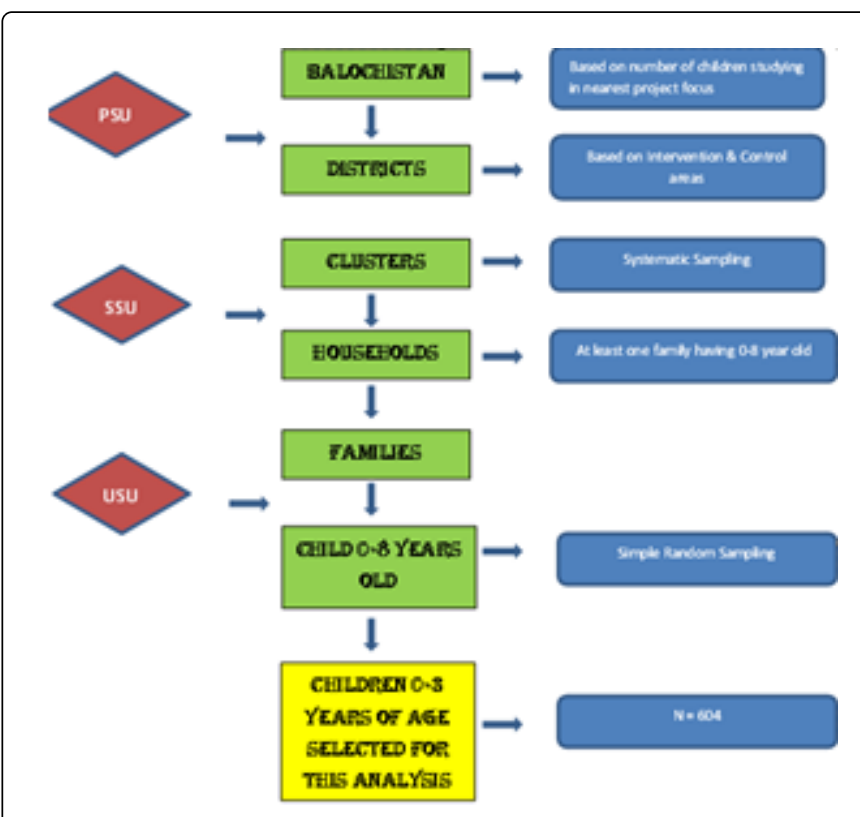

Figure 1: Sampling technique of baseline study (PSU: Primary Sampling Unit; SSU: Secondary Sampling Unit; USU: Usual Sampling Unit).

\section{Measures}

\section{Breastfeeding measure}

Information regarding the breastfeeding initiation and duration of exposure was obtained retrospectively from the child's mother. The mother was asked whether the study child was ever breastfed and the duration of exposure to breastfeeding was recorded in months and weeks. The duration of breastfeeding was treated as a categorical variable i-e breastfeeding duration less than 6 months, breastfeeding duration greater than 6 and less than 12 months and lastly breastfeeding duration greater than 12 months. The reason for this categorization was to determine the cut-off level of the duration of breastfeeding which leads to improvement in cognition and language.

\section{Language and cognitive outcome measure}

To measure the language and cognitive development of children, CDA (Care for Development Appraisal) tool was applied. It assess the development of children in five domains; gross motor, fine motor, language, cognitive and social-emotional development [7]. For each domain it assesses whether or not age appropriate indicator for the child has been achieved. Thus it gave a binary outcome for the cognitive and language development of children.

\section{Co-variates}

Parenteral nurturance is considered an important factor in a child's developmental trajectory. We used the HOME (Home Observation for Measurement of the Environment) inventory to assess the quality and quantity of support and stimulation provided for children at home [8]. The HOME scale is further distributed over six subscales. Each subscale has a set of questions with a binary outcome. No cut-off points are specified in the HOME manual and the scores falling into the lowest quarter, middle half and upper quarter are reported. High scores, falling in the upper quarter category, indicate a safer and stimulating home environment for healthy child development whereas home scores falling into the lowest quarter are considered as a risk for development [8]. Frequency distributions of all responses and mean and standard deviation for all subscales were calculated. Each sub-scale was adjusted for the multivariate regression. We also included the monthly income of the family, the type of construction of the house and house ownership as proxy indicators for capturing the socioeconomic status of the participants. The data for joint vs. nuclear family was also taken as it was our hypothesis that children living in joint families receive more stimulation as compared to those living solely with the parents. We also adjusted for stunting and immunization coverage as indicators of a child's medical health.

\section{Results}

The Table 1 shows that $64.4 \%$ of the children were breastfed for more than a year. Children having age appropriate cognitive and language development were $93.4 \%$ and $94.5 \%$ respectively. $98.8 \%$ of the children belonged to Islamic families. $30 \%$ of our sample was taken from Gwadar, 36\% from Quetta and 34\% from Muslim Bagh. 50.5\% children were boys and the rest were girls. Most of the children belonged to poor families, $50.8 \%$ having family income less than Rs. 10 , $000 /$ month. $36.9 \%$ of the children lived in a "Kacha" house and $25.8 \%$, $37.3 \%$ lived in a "Semi-Pakka" and "Pakka" house respectively. 
Citation: Iqbal M, Rafique G, Ali S (2017) The Effect of Breastfeeding on the Cognitive and Language Development of Children Under 3 Years of Age: Results of 'Balochistan-Early Childhood Development Project'. J Gen Pract (Los Angel) 5: 305. doi:10.4172/2329-9126.1000305

\begin{tabular}{|c|c|}
\hline Variables & Frequencies (percentages) \\
\hline \multicolumn{2}{|l|}{ Duration of Breastfeeding } \\
\hline Less than 6 months & $88(14.6)$ \\
\hline Greater than 6 , less than 12 months & $127(21.0)$ \\
\hline Greater than 12 months & $389(64.4)$ \\
\hline \multicolumn{2}{|l|}{ Cognitive Development } \\
\hline Yes & $564(93.4)$ \\
\hline No & $40(6.6)$ \\
\hline \multicolumn{2}{|l|}{ Language Development } \\
\hline Yes & $571(94.5)$ \\
\hline No & $33(5.5)$ \\
\hline \multicolumn{2}{|l|}{ Gender } \\
\hline Male & $305(50.5)$ \\
\hline Female & $299(49.5)$ \\
\hline \multicolumn{2}{|l|}{ Monthly income of the family } \\
\hline Income less than Rs. 10000 & $307(50.8)$ \\
\hline Income>Rs. 10000 and <Rs. 15000 & $153(25.3)$ \\
\hline Income greater than Rs. 15000 & $144(23.8)$ \\
\hline \multicolumn{2}{|l|}{ House Ownership } \\
\hline Owns the house & $488(80.8)$ \\
\hline Does not own the house & $116(19.2)$ \\
\hline \multicolumn{2}{|l|}{ Construction of house } \\
\hline Pakka & $225(37.3)$ \\
\hline Semi pakka & $156(25.8)$ \\
\hline Kacha & $223(36.9)$ \\
\hline \multicolumn{2}{|l|}{ Stunting } \\
\hline Present & $240(40.5)$ \\
\hline Not Present & $352(59.5)$ \\
\hline \multicolumn{2}{|l|}{ Immunization } \\
\hline Completely Immunized & $431(71.4)$ \\
\hline Not immunized & $173(28.6)$ \\
\hline \multicolumn{2}{|l|}{ Nuclear/Joint Family } \\
\hline Nuclear family & $256(42.4)$ \\
\hline Joint family & $348(57.6)$ \\
\hline \multicolumn{2}{|l|}{ Home Inventory (Mean+SD) } \\
\hline Responsivity (11) & $8.95(1.95)$ \\
\hline
\end{tabular}


Citation: Iqbal M, Rafique G, Ali S (2017) The Effect of Breastfeeding on the Cognitive and Language Development of Children Under 3 Years of Age: Results of 'Balochistan-Early Childhood Development Project'. J Gen Pract (Los Angel) 5: 305. doi:10.4172/2329-9126.1000305

Page 4 of 8

\begin{tabular}{|l|l|}
\hline Acceptance (8) & $5.34(2.16)$ \\
\hline Organization (6) & $4.25(1.32)$ \\
\hline Learning material (9) & $1.89(2.57)$ \\
\hline Involvement (6) & $3.54(1.74)$ \\
\hline Variety (5) & $2.93(0.89)$ \\
\hline
\end{tabular}

Table 1: Descriptive statistics of the sample population.

The data regarding birth weight of the child and the gestational age at the time of delivery were taken through maternal recall. $98 \%$ of the children were full term at birth. For $92 \%$ of the participants, the birth weight was not known by the mother. Only $2.3 \%$ of the participants had birth weight below $2.5 \mathrm{~kg}$. For $71.4 \%$ of the children, the mothers reported that they were completely immunized according to EPI schedule. When asked about the age of weaning, $35 \%$ children were started on semi-solid food before 6 months and $50 \%$ were first given semi-solid food at 6 months. $57.6 \%$ children lived in a joint family. Height and weight of the children were measured at the time of the interview. Stunting was determined using the WHO standard z-score charts. It was seen that $40.5 \%$ of the children were stunted (Table 1 ).

Table 2 shows that $94.9 \%$ and $95.6 \%$ of the children who were breastfed for more than 12 months had age appropriate cognitive and language development as compared to $86.4 \%$ and $88.6 \%$ of children breastfed less than 6 months respectively ( $\mathrm{p}$-value $<0.05$ ) (Table 2).

Table 3 shows the results of uni-variate and multi-variate logistic regression for cognition. It shows that after adjusting for co-variates, the odds of cognitive development were 2.42 times more in children who were breastfed for more than 12 months as compared to those who were breastfed for less than 6 months $(\mathrm{p}<0.05)$. Cognitive development was $53 \%$ more in girls as compared to boys $(\mathrm{p}=0.039)$. The odds of cognitive development improved with greater household income, having a "pakka" residence vs. a "kacha". The cognitive development was also more in children who were immunized $(\mathrm{aOR}=1.90)$ and were not stunted $(\mathrm{aOR}=1.71)$. However these results were not statistically significant ( $\mathrm{p}>0.05)$ (Table 3 ).

Table 4 shows the crude and adjusted ORs for Language development in children. It was determined that after adjusting for other possible factors, the odds of language development were 2.44 times more in children breastfed more than 12 months as compare to children breastfed less than 6 months $(\mathrm{p}<0.05)$. The children who were completely immunized also were at an advantage for language development $(\mathrm{aOR}=2.91, \mathrm{p}=0.006$ ). Surprisingly, our study did not reveal any positive impact of parenteral nurturance on cognitive or language development of children as measured by the HOME inventory (Table 4).

\begin{tabular}{|c|c|c|c|c|}
\hline \multirow{2}{*}{ Characteristics } & $\begin{array}{l}\text { Breastfeeding less than } 6 \\
\text { months }\end{array}$ & $\begin{array}{l}\text { Breastfeeding greater than } 6 \text {, less } \\
\text { than } 12 \text { months }\end{array}$ & $\begin{array}{l}\text { Breastfeeding greater than } 12 \\
\text { months }\end{array}$ & \multirow[t]{2}{*}{$P$ value } \\
\hline & $\mathrm{N}(\%)$ & $\mathrm{N}(\%)$ & $\mathrm{N}(\%)$ & \\
\hline \multicolumn{5}{|l|}{ Cognitive development } \\
\hline Yes & $76(86.4)$ & $119(93.7)$ & 369 (94.9) & \multirow[t]{2}{*}{$<0.05$} \\
\hline No & $12(13.6)$ & $8(6.3)$ & $20(5.1)$ & \\
\hline \multicolumn{5}{|l|}{ Language Development } \\
\hline Yes & $78(88.6)$ & $121(95.3)$ & $372(95.6)$ & \multirow[t]{2}{*}{$<0.05$} \\
\hline No & $10(11.4)$ & $6(4.7)$ & $17(4.4)$ & \\
\hline \multicolumn{5}{|l|}{ Gender } \\
\hline Male & $46(52.3)$ & $51(40.2)$ & $208(53.5)$ & \multirow[t]{2}{*}{$<0.05$} \\
\hline Female & $42(47.7)$ & $76(59.8)$ & $181(46.5)$ & \\
\hline \multicolumn{5}{|l|}{ Monthly income of the family } \\
\hline Income less than Rs. 10000 & $38(43.2)$ & $75(59.1)$ & $194(49.9)$ & \multirow{3}{*}{0.199} \\
\hline $\begin{array}{l}\text { Income }>\text { Rs. } 10000 \text { and }<\text { Rs. } \\
15000\end{array}$ & $27(30.7)$ & $28(22)$ & $98(25.2)$ & \\
\hline Income greater than Rs. 15000 & $23(26.1)$ & $24(18.9)$ & $97(24.9)$ & \\
\hline
\end{tabular}


Citation: Iqbal M, Rafique G, Ali S (2017) The Effect of Breastfeeding on the Cognitive and Language Development of Children Under 3 Years of Age: Results of 'Balochistan-Early Childhood Development Project'. J Gen Pract (Los Angel) 5: 305. doi:10.4172/2329-9126.1000305

Page 5 of 8

\begin{tabular}{|c|c|c|c|c|}
\hline \multicolumn{5}{|l|}{ House ownership } \\
\hline owns the house & $72(81.8)$ & $103(81.1)$ & $313(80.5)$ & \multirow[t]{2}{*}{0.954} \\
\hline does not own the house & $16(18.2)$ & $24(18.9)$ & $76(19.5)$ & \\
\hline \multicolumn{5}{|l|}{ Construction of house } \\
\hline Kacha & $24(27.3)$ & $80(63.0)$ & $119(30.6)$ & \multirow{3}{*}{$<0.05$} \\
\hline Semi pakka & $21(23.9)$ & $18(14.2)$ & $117(30.1)$ & \\
\hline Pakka & $43(48.9)$ & $29(22.8)$ & $153(39.3)$ & \\
\hline \multicolumn{5}{|l|}{ Stunting } \\
\hline Yes & $42(50.0)$ & $37(29.6)$ & $161(42.0)$ & \multirow[t]{2}{*}{$<0.05$} \\
\hline No & $42(50.0)$ & $88(70.4)$ & $222(58.0)$ & \\
\hline \multicolumn{5}{|l|}{ Immunization } \\
\hline Immunized & $59(67.0)$ & $79(62.2)$ & $293(75.3)$ & \multirow[t]{2}{*}{$<0.05$} \\
\hline Not immunized & $29(33.0)$ & $48(37.8)$ & $96(24.7)$ & \\
\hline \multicolumn{5}{|l|}{ Nuclear/Joint Family } \\
\hline Nuclear family & $39(44.3)$ & $60(47.2)$ & $157(40.4)$ & \multirow[t]{2}{*}{0.365} \\
\hline Joint family & $49(55.7)$ & $67(52.8)$ & $232(59.6)$ & \\
\hline
\end{tabular}

Table 2: Descriptive statistics of children according to the duration of breastfeeding.

\begin{tabular}{|c|c|c|c|}
\hline Variables & Unadjusted OR (95\%Cl) & Adjusted OR $(95 \% \mathrm{Cl})^{*}$ & $P$ value \\
\hline \multicolumn{4}{|l|}{ Duration of Breastfeeding } \\
\hline Less than 6 months & 1 & 1 & \multirow{3}{*}{$<0.05$} \\
\hline Greater than 6 , less than 12 months & $2.34(0.91-6.01)$ & $1.91(0.67-5.47)$ & \\
\hline Greater than 12 months & $2.91(1.36-6.21)$ & $2.42(1.05-5.57)$ & \\
\hline \multicolumn{4}{|l|}{ Gender } \\
\hline Male & $0.52(0.27-1.03)$ & $0.47(0.23-0.96)$ & $<0.05$ \\
\hline \multicolumn{4}{|l|}{ Monthly income of the family } \\
\hline Income less than Rs. 10000 & 1 & 1 & \multirow{2}{*}{0.206} \\
\hline Income > Rs. 10000 and <Rs. 15000 & $0.64(0.31-1.29)$ & $0.61(0.29-1.30)$ & \\
\hline Income greater than Rs. 15000 & $1.93(0.71-5.27)$ & $1.58(0.55-4.51)$ & 0.392 \\
\hline \multicolumn{4}{|l|}{ House Ownership } \\
\hline Owns the house & $0.58(0.22-1.52)$ & & \\
\hline \multicolumn{4}{|l|}{ Construction of house } \\
\hline Kacha & 1 & 1 & \multirow{2}{*}{0.087} \\
\hline Semi pakka & $1.30(0.64-2.63)$ & $2.43(0.87-6.72)$ & \\
\hline Pakka & $2.32(0.90-5.97)$ & $1.72(0.73-4.03)$ & 0.211 \\
\hline
\end{tabular}


Citation: Iqbal M, Rafique G, Ali S (2017) The Effect of Breastfeeding on the Cognitive and Language Development of Children Under 3 Years of Age: Results of 'Balochistan-Early Childhood Development Project'. J Gen Pract (Los Angel) 5: 305. doi:10.4172/2329-9126.1000305

Page 6 of 8

\begin{tabular}{|c|c|c|c|}
\hline \multicolumn{4}{|l|}{ Stunting } \\
\hline Not Present & $1.77(0.92-3.41)$ & $1.71(0.85-3.44)$ & 0.128 \\
\hline \multicolumn{4}{|l|}{ Immunization } \\
\hline Completely Immunized & $1.72(0.89-3.34)$ & $1.90(0.88-4.09)$ & 0.098 \\
\hline \multicolumn{4}{|l|}{ Nuclear/Joint Family } \\
\hline Nuclear family & $1.39(0.71-2.73)$ & & \\
\hline \multicolumn{4}{|l|}{ Home Inventory } \\
\hline Responsivity (11) & $1.17(0.98-1.14)$ & $1.16(0.98-1.37)$ & 0.082 \\
\hline Acceptance (8) & $0.90(0.77-1.06)$ & $0.89(0.75-1.06)$ & 0.205 \\
\hline Organization (6) & $1.04(0.77-1.40)$ & & \\
\hline Learning material (9) & $0.88(0.76-1.01)$ & \multirow[t]{3}{*}{$0.87(0.75-1.00)$} & \multirow[t]{3}{*}{0.051} \\
\hline Involvement (6) & $0.91(0.73-1.14)$ & & \\
\hline Variety (5) & $1.17(0.75-1.81)$ & & \\
\hline
\end{tabular}

Table 3: Results of multiple logistic regressions for cognition.

\begin{tabular}{|c|c|c|c|}
\hline Variables & Unadjusted OR (95\%Cl) & Adjusted OR $(95 \% \mathrm{Cl})^{*}$ & $P$ value \\
\hline \multicolumn{4}{|l|}{ Duration of Breastfeeding } \\
\hline Less than 6 months & 1 & 1 & \multirow{3}{*}{$<0.05$} \\
\hline Greater than 6 ,less than 12 months & $2.58(0.90-7.39)$ & $2.20(0.73-6.55)$ & \\
\hline Greater than 12 months & $2.80(1.23-6.35)$ & $2.44(1.05-5.70)$ & \\
\hline \multicolumn{4}{|l|}{ Gender } \\
\hline Male & $0.56(0.27-1.17)$ & $0.49(0.23-1.05)$ & 0.067 \\
\hline \multicolumn{4}{|l|}{ Monthly income of the family } \\
\hline Income less than Rs. 10000 & 1 & & \\
\hline Income > Rs. 10000 and <Rs. 15000 & $1.22(0.49-3.01)$ & & \\
\hline Income greater than Rs. 15000 & $0.87(0.38-2.02)$ & & \\
\hline \multicolumn{4}{|l|}{ House Ownership } \\
\hline Owns the house & $1.35(0.51-3.57)$ & & \\
\hline \multicolumn{4}{|l|}{ Construction of house } \\
\hline Kacha & 1 & & \\
\hline Semi pakka & $1.42(0.56-3.61)$ & & \\
\hline Pakka & $1.18(0.53-2.63)$ & & \\
\hline \multicolumn{4}{|l|}{ Stunting } \\
\hline Present & $1.50(0.73-3.06)$ & & \\
\hline Immunization & & & \\
\hline
\end{tabular}


Citation: Iqbal M, Rafique G, Ali S (2017) The Effect of Breastfeeding on the Cognitive and Language Development of Children Under 3 Years of Age: Results of 'Balochistan-Early Childhood Development Project'. J Gen Pract (Los Angel) 5: 305. doi:10.4172/2329-9126.1000305

Page 7 of 8

\begin{tabular}{|c|c|c|c|}
\hline Completely Immunized & $2.48(1.22-5.03)$ & $2.91(1.36-6.22)$ & 0.006 \\
\hline \multicolumn{4}{|l|}{ Nuclear/Joint Family } \\
\hline Nuclear family & $1.74(0.81-3.72)$ & $1.77(0.82-3.85)$ & 0.145 \\
\hline \multicolumn{4}{|l|}{ Home Inventory } \\
\hline Responsivity (11) & $1.07(0.88-1.30)$ & & \\
\hline Acceptance (8) & $0.94(0.79-1.11)$ & & \\
\hline Organization (6) & $1.01(0.73-1.39)$ & & \\
\hline Learning material (9) & $0.88(0.76-1.03)$ & $0.91(0.79-1.04)$ & 0.192 \\
\hline Involvement (6) & $1.06(0.83-1.36)$ & & \\
\hline Variety (5) & $1.11(0.69-1.80)$ & & \\
\hline
\end{tabular}

Table 4: Results of multivariate logistic regression for language.

\section{Discussion}

The results of the current study indicate that increasing the duration of breastfeeding ( $>12$ months) during infancy was significantly associated with improvement in the cognitive and language development of children even after adjusting for a range of child and socio-economic and socio-environmental factors $(\mathrm{aOR}=2.42$, $\mathrm{aOR}=2.44$ respectively). The biologic plausibility for this association lies in the hypothesis that the breast milk has long chain polyunsaturated fatty acids (PUFAs) which are not present in the cow's milk. These bio-active compounds are found in high concentrations in the brain and the retina. It is thought that these compounds have a beneficial effect on the visual and neuro-cognitive development during the early years of neuro-maturation thus leading to significantly improved cognitive and language development in infants [9].

Similar findings have been reported by other studies that the language and cognitive outcomes are better in breastfed children as compared to bottle fed children. Also, increasing the dose (duration) of breastfeeding leads to protection against delays in children's language development $[10,11]$.

Immunization played an important role in the language development of children under 3 years of age. Children who were completely immunized were 2.91 times more likely to achieve age appropriate language development as compared to non-immunized children $(\mathrm{p}=0.006)$. A possible explanation for this association could be that non-immunized children suffer more from childhood diseases. During episodes of disease, the child is lethargic and less susceptible to human stimulation, thus losing the time for further development. Chronic diseases also result in stunting which is a proven risk factor for developmental delays in children [12].

Limited data is available in the context of Pakistan regarding the association between breastfeeding and language and cognitive development of children. $94 \%$ of children of Pakistan are reported to have been breastfed at some-time [13]. A major strength of our study was to reveal this association. We also utilized HOME, which is a validated tool for measuring the effect of the home environment on the child. We would further argue that robust techniques of analysis were applied and a wide range of co-variates were adjusted. An obvious limitation of our study is that we did not have data regarding the maternal IQ to be adjusted in our analysis. Some studies suggest that the difference in IQ of children is solely based on maternal IQ and when that is adjusted the difference vanishes [3]. Some studies take maternal education as a proxy indicator for maternal IQ, but we did not think that to be appropriate [14]. We also could not account for several other factors which play an important role in the development of children. Lastly, we cannot exclude the possibility of recall bias affecting the data regarding the duration of breastfeeding. Eaton et al. [15] found out that for children under 3 years of age, 79\% of the mothers were able to accurately recall the duration of breastfeeding within a month and $95 \%$ to within 2 months.

\section{Conclusion}

Based on our findings, we recommend that breastfeeding should be promoted for greater than 12 months. It leads to improved child's language and cognitive development and also helps to build a bond between the mother and the child. However, we need more robust studies, including trials to establish the causal association between the duration of breastfeeding and a child's language and cognitive development.

\section{Declarations}

Ethics approval and consent to participate: Before starting the project, clearance was obtained from the Ethical Review Committee of Aga Khan University, Pakistan. Prior to administering the questionnaire to the participants, an informed consent was obtained from the mothers of the children.

Consent for publication: Written informed consent for publication was obtained from all the mothers of the participants.

Availability of data and material: The datasets analyzed for this paper are available from the corresponding author on reasonable request.

Funding: "Balochistan-Early Childhood Development Project" was led by Aga Khan Foundation, Pakistan (AKF, P) and funded by 
Citation: Iqbal M, Rafique G, Ali S (2017) The Effect of Breastfeeding on the Cognitive and Language Development of Children Under 3 Years of Age: Results of 'Balochistan-Early Childhood Development Project'. J Gen Pract (Los Angel) 5: 305. doi:10.4172/2329-9126.1000305

Page 8 of 8

AusAID. This agency was involved in setting up the Family Resource Centres, FRCs in the districts of Balochistan.

\section{Authors' contributions}

MI came up with the conception and design of the study. She analyzed and interpreted the data. She was a major contributor in writing the manuscript. GR critically revised the content of the manuscript and gave final approval of the manuscript to be published. SA analyzed and interpreted the data.

\section{Acknowledgements}

"Balochistan-Early Childhood Development Project" was led by Aga Khan Foundation, Pakistan (AKF,P) and funded by AusAID. It was planned in consultation with two technical partners; Institute for Education Development (IED) and Human Development Programme (HDP) of Aga Khan University and three implementing partners (Rural Community Development Council, Taraqee Foundation, Institute for Development Studies and Practices) and the Government of Balochistan. In addition to the funders and the project team, we would also like to thank the families and the children who participated in the study and provided data for this paper.

\section{References}

1. Webb K, Stickney B, Heywood P (2005) Breastfeeding and the public's health. NSW Public Health Bull. 16: 42-46.

2. Anderson JW, Johnstone BM, Remley DT (1999) Breast-feeding and cognitive development: a meta-analysis. Am J Clin Nutr 70: 525-535.

3. Walfisch A, Sermer C, Cressman A, Koren G (2013) Breast milk and cognitive development- the role of confounders: a systematic review. J Neurointerv Surg, BMJ 3: e003259.
4. Leventakou V, Roumeliotaki T, Koutra K, Vassilaki M, Mantzouranis E, et al. (2015) Breastfeeding duration and cognitive, language and motor development at 18 months of age: Rhea mother-child cohort in Crete, Greece. J Epidemiol Community Health BMJ 69: 232-239.

5. Kramer MS, Kakuma R (2001) The optimal duration of exclusive breastfeeding Report of an expert consultation. Geneva Switzerland: World Health Organization 28-36.

6. (2012) AKU-HDP. Balochistan-Early Childhood Development Project; Family Resource Center: Baseline Survey Report. Pakistan: AKU p: 95.

7. Nadeem S, Avan BI, Rafique G (2016) Development of child assessment and caregiver advice manual for front line health workers to enhance early child development in developing world. J Child Dev Disord 2:1.

8. Nadeem S, Rafique G, Khowaja L, Yameen A (2014) Assessing home environment for early child development in Pakistan. Child Care Pract 20:194-206.

9. Jiao J, Li Q, Chu J, Zeng W, Yang M,et al. (2014) Effect of n- 3 PUFA supplementation on cognitive function throughout the life span from infancy to old age: a systematic review and meta-analysis of randomized controlled trials. AM J Clin Nutr 100: 1422-1436.

10. Smith JM (2015) Breastfeeding and language outcomes: A review of the literature. J Commun Disord 57: 29-40.

11. Dee DL, Li R, Lee LC, Grummer-Strawn LM (2007) Associations between breastfeeding practices and young children's language and motor skill development. Am Acad Pediatr 119: S92-S98.

12. Walker SP, Wachs TD, Gardner JM, Lozoff B, Wasserman GA, et al. (2007) Child development: risk factors for adverse outcomes in developing countries. The Lancet 369:145-157.

13. (2013) National Institute of Population Studies (NIPS) Pakistan, ICF International. Pakistan demographic and health survey 2012-13. p: 366.

14. Mc Crory C, Layte R (2011) The effect of breastfeeding on children's educational test scores at nine years of age: Results of an Irish cohort study. Soc Sci Med 72: 1515-1521.

15. Eaton-Evans J, Dugdale AE (1986) Recall by mothers of the birth weights and feeding of their children. Hum Nutr Appl Nutr 40: 171-175. 